\title{
Evolução da qualidade dos recursos hídricos de Lavras Novas, Ouro Preto-MG, a partir da percepção de autóctones e de análises microbiológicas e físico-químicas
}

\author{
Guilherme Fortes Drummond Chicarino Varajão*
}

Alexandre Magno Alves Diniz

\section{Resumo}

O presente trabalho teve como foco as análises físico-química e microbiológica dos recursos hídricos de Lavras Novas, distrito de Ouro Preto-MG. Os resultados encontrados foram comparados com os parâmetros estabelecidos pela legislação brasileira e com outros estudos em áreas com características naturais semelhantes, possibilitando a identificação de anomalias oriundas de atividades antrópicas. A partir da percepção dos autóctones foi possível concluir que houve sensíveis variações na qualidade das águas ao longo dos últimos anos. O estudo aponta a limitação da abrangência de determinados condicionantes naturais nos parâmetros legais do Brasil e sugere alguns aspectos críticos que merecem atenção para a mitigação dos problemas de contaminação identificados em Lavras Novas.

Palavras-chave: Lavras Novas; Recursos hídricos; Geoquímica; Coliforme fecal; Percepção ambiental

* Universidade Federal dos Vales do Jequitinhonha - Mucuri (guilhermefdcv@gmail.com).

** Pontifícia Universidade Católica de Minas Gerais - PUC-MG (dinizalexandre@terra.com.br).

Geosul, Florianópolis, v. 29, n. 57, p 65-88, jan./jun. 2014 
VARAJÃO, G.F.D.C. \& DINIZ, A.M.A. Evolução da qualidade dos recursos ...

The evolution in the quality of water resources from Lavras Novas,

Ouro Preto-MG, based on the perception of the local population and on physical-chemical and microbiological analysis

\begin{abstract}
This study focused on the physical-chemical and microbiological analysis of the water resources in Lavras Novas, district of Ouro Preto-MG. The results were compared with the parameters established by the Brazilian legislation and with other studies in areas with similar natural characteristics, enabling the identification of anomalies derived from anthropogenic activities. Based on the perception of the local population it was concluded that there have been noticeable variations in water quality over the past few years. The study points out the limitation of the scope of certain natural conditions in the legal parameters of Brazil and suggests some critical aspects that deserve attention to mitigate the identified contamination problems in Lavras Novas.
\end{abstract}

Key words: Lavras Novas; Water resources; Geochemistry; Fecal coliform; Environmental perception.

\title{
Introdução
}

Com origens no período colonial de exploração do ouro, Lavras Novas manteve suas principais características até meados do século XX, sofrendo grandes transformações induzidas pelo turismo a partir da década de 1990. Assim como grande parte de núcleos urbanos da América Latina, este distrito de Ouro PretoMG possui grandes limitações em relação ao serviço de saneamento público, que não acompanhou o rápido crescimento populacional da localidade.

A pesquisa teve como uma das suas finalidades a análise físicoquímica e microbiológica dos recursos hídricos, de maneira a aferir a qualidade dos mesmos, buscando saber se estes apresentam significativas alterações antrópicas. Sob a lente de uma perspectiva 
VARAJÃO, G.F.D.C. \& DINIZ, A.M.A. Evolução da qualidade dos recursos ... sistêmica, os cursos d'água representam uma das saídas (output) do sistema, delimitado pelas microbacias, de modo que o resultado de suas análises reflete muito dos condicionantes da paisagem de Lavras Novas, constituída por elementos naturais e humanos.

A comparação dos resultados encontrados nas águas das drenagens do entorno do distrito de Lavras Novas com pesquisas em Unidades de Conservação adjacentes, de certa forma tidas como referência ou background, permitiu avaliar as diferentes intensidades das atividades antrópicas. As análises traçam um quadro do momento em que foram coletadas as amostras de água, mas não indicam a situação em que se encontravam os recursos hídricos no passado. Entretanto, a partir do depoimento dos moradores mais antigos, constatou-se a percepção que esses possuem sobre as alterações sofridas pelos cursos d'água ao longo do tempo, e as formas de utilização dos mesmos no passado e na atualidade.

\section{Contextualização geográfica da área de estudo}

A região foco deste estudo se estende por uma área de aproximadamente 1200 hectares, compreendida entre os paralelos $20^{\circ} 26^{\prime} 32^{\prime \prime}$ e $20^{\circ} 29^{\prime} 15^{\prime \prime}$ de latitude sul e os meridianos $43^{\circ} 32^{\prime}$ 13 " e $43^{\circ} 29^{\prime} 18^{\prime \prime}$ de longitude oeste, situada no distrito de Lavras Novas, domínio do município de Ouro Preto, na parte central do Estado de Minas Gerais (Figura 1). Geologicamente o Distrito de Lavras Novas encontra-se na unidade litoestratigráfica do grupo Itacolomi, na borda sudeste do Quadrilátero Ferrífero, que consiste em uma das mais importantes províncias minerais do Brasil, sendo também caracterizada por outras três grandes unidades litoestratigráficas (ALKMIM; MARSHAK, 1998): Embasamento Cristalino, Supergrupo Rio das Velhas e o Supergrupo Minas.

Distando 110 quilômetros de Belo Horizonte, o acesso principal ao distrito se dá, em parte, pela estrada MG 129, que liga Ouro Preto a Ouro Branco, sendo o restante do trajeto realizado através de sete quilômetros de estrada não pavimentada. Assim, o núcleo urbano de Lavras Novas, situado a uma altitude média de 
VARAJÃO, G.F.D.C. \& DINIZ, A.M.A. Evolução da qualidade dos recursos ...

1350 metros acima do nível do mar, está inserido em um espaço intersticial entre a rodovia federal BR 356 e a rodovia estadual MG 129, em uma área de importante soerguimento do relevo.

De acordo com a classificação de Koppen, o clima da região encontra-se no domínio do clima subtropical de altitude $(\mathrm{CWb})$, que é caracterizado por duas estações bem definidas, um período seco no inverno, entre os meses de maio a agosto, e outro úmido, no verão, entre os meses de novembro e fevereiro (JOHNSON, 1962). A temperatura média anual varia entre $17-19^{\circ} \mathrm{C}$, com mínima a $5^{\circ} \mathrm{C}$ e máxima a $30^{\circ} \mathrm{C}$.
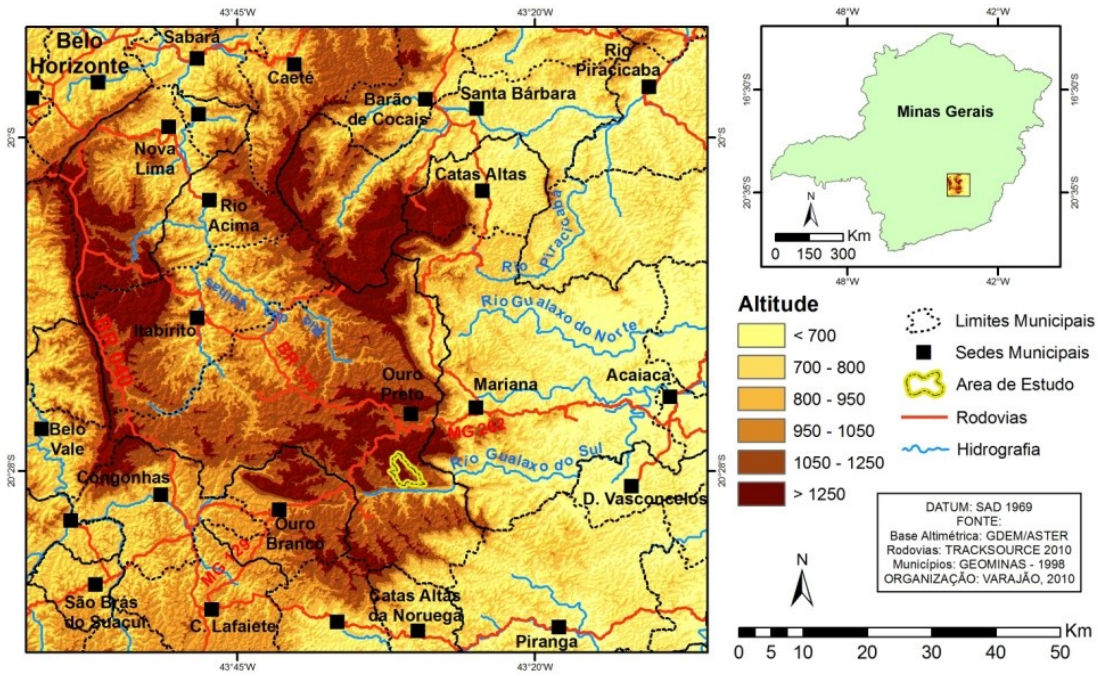

Figura 1: Mapa de localização da área de estudo

Na região de estudo são encontrados os biomas de transição entre Floresta Atlântica e Cerrado. Dentre as diversas tipologias florestais que ocorrem nesses biomas, a principal identificada na região é Floresta Estacional Semidecidual. Nas partes mais elevadas, em geral acima de 1300 metros, ocorrem os Campos Rupestres ou Campos de Altitude, constituídos por uma vegetação rasteira, predominantemente formada por gramíneas. 
VARAJÃO, G.F.D.C. \& DINIZ, A.M.A. Evolução da qualidade dos recursos ...

A área objeto deste estudo ocorre majoritariamente sobre rochas do Grupo Itacolomi, que é constituído predominantemente por quartzitos, com lentes de metaconglomerados, e, intercalações de metapelitos (xistos e filitos) (LOBATO et al., 2005). É bordejada ao sul por rochas metavulcânicas e metapelíticas do Grupo Nova Lima (Supergupo Rio das Velhas) e rochas granito-gnáissicas do embasamento cristalino; e, ao norte, predominantemente por xistos e filitos do Grupo Sabará (Supergrupo Minas).

Estas variações litológicas resultam no desenvolvimento de perfis de solos pouco evoluídos, variando de Neossolos litólicos, Neossolos Regolíticos a Cambissolos Háplicos (EMBRAPA, 2006). Os Neossolos são relacionados aos quartzitos e ocorrem em associação com áreas escarpadas com afloramentos de rochas. Os Cambissolos são relacionados à presença de rochas metapelíticas que favorecem o desenvolvimento de perfis de solos um pouco mais desenvolvidos.

\section{Metodologia}

A análise das águas foi realizada com o objetivo de registrar possíveis anomalias, adotando os padrões da legislação e dos trabalhos em litologias quartzíticas. O monitoramento da qualidade das águas consistiu em análises microbiológicas e físico-químicas, segundo normas da Associação Americana de Saúde Pública (APHA, 2005), em 16 pontos de águas de superfície nas microbacias do entorno de Lavras Novas, em três poços artesianos do núcleo urbano (águas subterrâneas) e, em três nascentes de água ou "bicas" usadas para consumo pela população, totalizando 22 amostras (Figura 2). A vazão dos cursos d'água foi medida segundo o método do flutuador, metodologia adaptada de Palhares et al. (2007).

Em alguns casos, as águas de um mesmo córrego foram analisadas em diferentes locais, franqueando a percepção das variações geradas principalmente a partir da confluência com outros cursos d'água, como no caso do Córrego da Brenha, que possui sua área de cabeceira afastada do centro urbano, mas que 
VARAJÃO, G.F.D.C. \& DINIZ, A.M.A. Evolução da qualidade dos recursos ... recebe as águas de três córregos que nascem na área urbana de Lavras Novas. Neste sentido, este arranjo amostral abrange algumas áreas de cabeceira dos córregos, que servem como pontos de controle e background, além de abranger algumas cachoeiras que são utilizadas para recreação, como a Cachoeira Três Pingos e a Cachoeira do Pocinho.

A campanha de amostragem das águas foi realizada entre os dias 01 e 03 de Agosto de 2010, no fim do período da estação seca, identificada com base nas séries históricas das estações pluviométricas em localidades próximas de Lavras Novas entre 1941 a 2005 (MINAS GERAIS, 2007). O período de amostragem também corresponde ao fim de uma época de intenso fluxo turístico na região, que ocorre no mês de julho, impulsionada pelo festival de inverno e os recessos escolares. Neste sentido, espera-se que as concentrações de efluentes nas águas sejam maiores, tendo em vista a baixa precipitação pluviométrica e, consequentemente, a menor vazão dos cursos d'água, facilitando a identificação de anomalias e possíveis interferências antrópicas, conforme indica estudo de Lopes et al. (2008).

Os resultados encontrados foram confrontados com a legislação brasileira vigente, que estabelece os padrões de balneabilidade (recreação de contato primário), segundo a Resolução CONAMA $\mathrm{n}^{\circ} 274$ (BRASIL, 2000); potabilidade (consumo humano), segundo a Portaria do Ministério da Saúde $n^{\circ} 2.914$ (BRASIL, 2011) e classifica os corpos de água com as diretrizes ambientais para o seu enquadramento de acordo com o tipo de uso (consumo humano, irrigação, etc.), segundo a Resolução CONAMA $\mathrm{n}^{\circ} 357$ (BRASIL, 2005).

Os resultados das análises físico-químicas também foram comparados com os valores obtidos nos cursos d'água do Parque Estadual do Itacolomi (ANDRADE et al. 2009; LEITE et al. 2010), que percolam a mesma unidade estratigráfica encontrada em Lavras Novas, especificamente os quartzitos do grupo Itacolomi, além dos trabalhos de Mourão (2007) e Salgado et al. (2004) nos quartzitos da formação Moeda (grupo Caraça), respectivamente nas 
VARAJÃO, G.F.D.C. \& DINIZ, A.M.A. Evolução da qualidade dos recursos ... proximidades da serra do Curral e na Reserva Santuário do Caraça (RPPN - Reserva Particular do Patrimônio Natural).

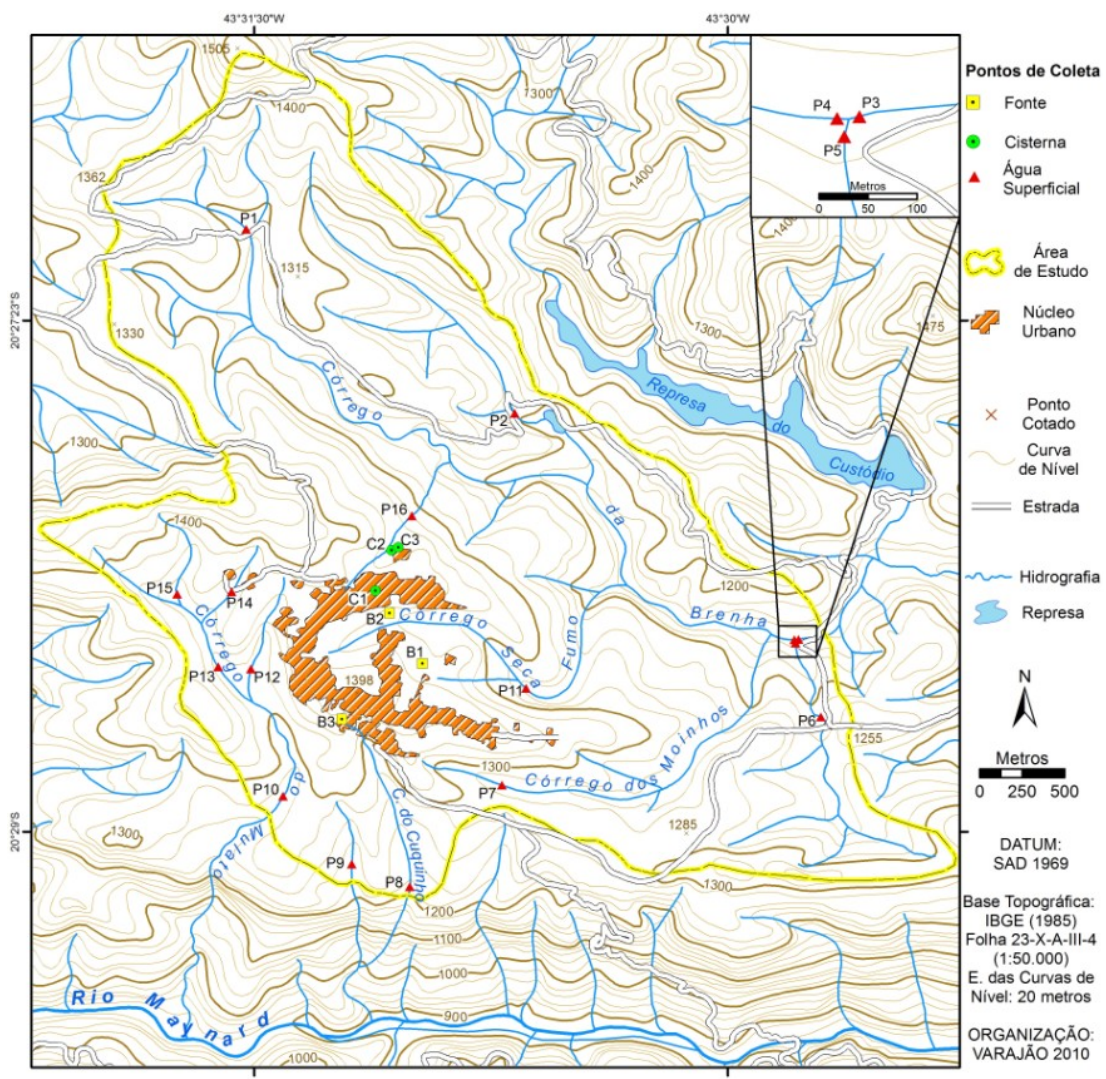

Figura 2: Mapa topográfico contendo os pontos de coleta no entorno de Lavras Novas e a delimitação da área de estudo.

Todos os resultados das análises foram apresentados em uma reunião com a comunidade de Lavras Novas, convocada pela associação de moradores e divulgada pela rádio Itatiaia de Ouro Preto. Este encontro, que contou com a presença de 25 pessoas 
VARAJÃO, G.F.D.C. \& DINIZ, A.M.A. Evolução da qualidade dos recursos ... residentes no distrito, teve por objetivo o registro das percepções dos habitantes em relação à evolução da qualidade das águas e das formas de utilização dos recursos hídricos no passado e no presente, evidenciando as alterações ao longo do tempo.

\section{Análise físico-química}

A litologia possui um papel crucial para a composição química dos rios (DREVER, 1997), sendo também controlada pelos processos bioquímicos dos solos (MOLDAN; CERNY, 1994). Segundo Mourão (2007), baseado nos conceitos de elaboração do Atlas de Águas Subterrâneas dos Estados Unidos (MILLER, 1999), aquíferos são constituídos por uma unidade geológica, um grupo de formações geológicas ou parte de uma formação suficientemente permeável de modo a permitir a produção significativa de água em poços e nascentes. Os sistemas aquíferos reúnem várias litologias de características hidráulicas, hidrodinâmicas e hidroquímicas relativamente semelhantes, em geral delimitados por camadas pouco permeáveis e representativas de um ambiente geológico.

A composição natural da água subterrânea é o resultado da combinação de vários fatores que incluem o tempo de residência da água na formação rochosa, a dissolução de minerais formadores das rochas pelas quais a água circula, a composição, granulometria, estrutura e espessura da zona não saturada e as características climáticas (MOURÃO, 2007). Neste sentido, os estudos sobre a influência geológica na assinatura química de águas no Parque Estadual do Itacolomi (ANDRADE et al., 2009; LEITE et al., 2010), unidade de conservação de proteção integral com baixa ação humana e próximo a área deste estudo, foram usados como parâmetro na identificação de possíveis interferências antrópicas. Baseou-se no pressuposto de que, tratando-se de uma mesma litologia (quartzitos do grupo Itacolomi) e que as duas áreas são contíguas, as concentrações químicas deveriam ser semelhantes. 
VARAJÃO, G.F.D.C. \& DINIZ, A.M.A. Evolução da qualidade dos recursos ...

Durante a campanha de amostragem, com o auxílio de um multiparâmetro portátil, modelo Ultrameter II da Fabricante Myron L. Co., foram mensurados in situ os parâmetros $\mathrm{pH}$, potencial redox $(\mathrm{mV})$, condutividade elétrica $(\mu \mathrm{S} / \mathrm{cm}-1)$, resistividade $(\mathrm{K} \Omega)$, sólidos totais dissolvidos $(\mathrm{mg} / \mathrm{L})$ e temperatura $\left({ }^{\circ} \mathrm{C}\right)$.

As amostras de água para análise química foram coletadas com auxílio de uma seringa de $60 \mathrm{ml}$ acoplada a um filtro com membrana de $0,45 \mu \mathrm{m}$ e condicionadas em frascos do tipo "pet" cristal de $30 \mathrm{ml}$, onde foram adicionadas três gotas de ácido nítrico $\left(\mathrm{HNO}_{3}\right)$ concentrado. Os frascos foram conservados em ambiente a $4^{\circ} \mathrm{C}$ até o momento da análise.

O espectrômetro de emissão atômica com fonte de plasma da marca Spectro, modelo Ciros CCD com Visão Radial, do laboratório de Geoquímica do Departamento de Geologia da Universidade Federal de Ouro Preto, foi utilizado na detecção dos seguintes elementos: Cálcio $(\mathrm{Ca})$, Potássio $(\mathrm{K})$, Magnésio $(\mathrm{Mg})$, Sódio $(\mathrm{Na})$, Fósforo $(\mathrm{P})$, Enxofre $(\mathrm{S})$, Silício $(\mathrm{Si})$, expressos em miligrama por litro (mg/L), e Alumínio (Al), Arsênio (As), Bário $(\mathrm{Ba})$, Berilo (Be), Cádmio (Cd), Cobalto (Co), Cromo (Cr), Cobre $(\mathrm{Cu})$, Ferro (Fe), Lítio (Li), Manganês (Mn), Molibdênio (Mo), Níquel (Ni), Chumbo (Pb), Escândio (Sc), Estrôncio (Sr), Titânio (Ti), Vanádio (V), Ítrio (Y) e Zinco (Zn), expressos em micrograma por litro $(\mu \mathrm{g} / \mathrm{L})$.

\section{Análises microbiológicas}

O grau de contaminação microbiológica das águas é comumente aferido com base na densidade de organismos indicadores, no pressuposto de que há uma relação direta entre os indicadores e a presença de agentes patogênicos. Membros do grupo das bactérias coliformes são usualmente empregados como indicadores de possível contaminação de esgoto (MORIÑIGO et al., 1990). Embora eles não sejam prejudiciais por conta própria, eles indicam a possível presença de outros agentes patogênicos comumente a eles associados, como bactérias, vírus e protozoários, 
VARAJÃO, G.F.D.C. \& DINIZ, A.M.A. Evolução da qualidade dos recursos ...

que também vivem no sistema digestivo humano e animal. Portanto, a presença destes organismos na água sugere que microorganismos patogênicos também podem estar presentes e o consumo e ou contato com estes representam riscos à saúde, devido à possibilidade de transmissão de doenças de veiculação hídrica, tais como febre tifóide, febre paratifóide, disenteria bacilar e cólera (CETESB, 2004). Além deste risco, o material fecal pode, ainda, causar uma série de impactos aos cursos d'água, tais como odores desagradáveis, aumento da turbidez da água e da demanda por oxigênio (DATES et al., 1994).

Dentro do grupo dos coliformes totais está contido o grupo dos coliformes termotolerantes, bactérias que fermentam a lactose a $44,5 \pm 0,2{ }^{\circ} \mathrm{C}$ em 24 horas, tendo como principal representante a Escherichia coli (E. coli). Trata-se de uma bactéria pertencente à família Enterobacteriaceae, sendo a única espécie do grupo dos coliformes termotolerantes, cujo habitat exclusivo é o intestino de animais homeotérmicos, incluindo os humanos, onde ocorre em densidades elevadas (BRASIL, 2005). Assim, o indicador mais utilizado para presença de contaminação fecal é a $E$. coli, apontando também uma contaminação fecal recente e a eventual presença de organismos patogênicos (BAUDISOVA, 1997). Essa bactéria sobrevive, em média, de quatro a 12 semanas, dependendo das condições ambientais, podendo viver ainda mais tempo em sistemas canalizados de distribuição (EDBERG et al., 2000).

As análises microbiológicas das águas coletadas em Lavras Novas consistiram na determinação dos números mais prováveis (NMP) de coliformes totais e, especificamente, Escherichia coli a partir de volumes de $100 \mathrm{ml}$ de cada amostra de água, utilizando-se do substrato enzimático cromogênico e fluorogênico ONPG/MUG para promover a reação durante a incubação por 24 horas à $35,5^{\circ} \mathrm{C}$ e possibilitar a utilização de tabela de leitura com base estatística (Quanti-tray 2000/Colilert - Idexx Laboratories).

As amostras de água foram coletadas em saco plástico estéril com tarja de identificação e capacidade de $100 \mathrm{ml}$, sendo armazenadas a uma temperatura inferior a $10^{\circ} \mathrm{C}$, por menos de 8 
VARAJÃO, G.F.D.C. \& DINIZ, A.M.A. Evolução da qualidade dos recursos ... horas, e analisadas no mesmo dia da coleta no Laboratório de Qualidade de Água da Escola de Farmácia da Universidade Federal de Ouro Preto.

\section{Evolução dos recursos hídricos de Lavras Novas}

No período anterior à última década do século XX, Lavras Novas não possuía adequado sistema de distribuição de água ou rede de esgoto. Os habitantes se sujeitavam a buscar água nas diversas nascentes d'água próximas as suas casas, conforme relato de Maria Raimunda Maia, moradora do povoado, transcrito por Teixeira (2004, p. 176): "a gente buscava na fonte, e às vezes era preciso paciência para esperar a vez na fila que se formava na bica”. Em geral, eram as mulheres as responsáveis por carregar as latas de água que utilizavam nas residências. $\mathrm{O}$ costume de buscar água na bica permanece até os dias atuais, uma vez que ainda se vê alguns autóctones enchendo galões de água para consumo próprio, sendo a água canalizada usada para os demais fins domésticos.

$\mathrm{O}$ adensamento urbano, em alguns casos, provocou a extinção de algumas nascentes, de acordo com relato de um morador do povoado há 44 anos, com 58 anos de idade: "Aqui atrás [porção de mata próxima ao quintal da casa do informante] tinha uma bica de água, uma nascente, a gente usava até pra lavar roupa, buscar água. Foram construindo aí em volta, tirando terra, aterrando outros lugares, agora não tem mas água não." (ALMASSY JUNIOR, 2004, p. 96).

Apesar dos autóctones constatarem que a qualidade dos recursos hídricos tem se deteriorado, poucos identificam as causas, uma vez que a maior parte desconhece as áreas de recarga dos aquíferos. Ornelas (2008) apontou que poucos residentes reconhecem na Serra do Trovão a principal fonte de água do distrito.

As obras de saneamento executadas pela Prefeitura Municipal de Ouro Preto, durante o governo de Wilson Milagres em 1991, resumiram-se em estabelecer uma canalização dos efluentes residenciais e despejá-los in natura nos córregos. Tratou- 
VARAJÃO, G.F.D.C. \& DINIZ, A.M.A. Evolução da qualidade dos recursos ... se de uma solução paliativa para o problema de saúde apresentado pelos moradores, que possuíam sistemas de fossa negra no fundo dos seus domicílios. Tal iniciativa também não previu o crescimento de Lavras Novas, que agravou o problema da qualidade de seus recursos hídricos com o passar dos anos.

Aqui foi só aumentando, mas na época era só a população nossa mesmo, né? Muita gente não tinha nem banheiro. Pra falar a verdade mesmo, eles tinham é fossa lá na horta. Aí fez o esgoto e foi bom, porque limpou. As crianças davam muito problema de diarreia e essas coisas, e isso aí eliminou porque jogou o esgoto lá pra longe. Mas contaminou a lagoa, por que não tinha outro jeito né? Melhora uma coisa e piora outra né? (Morador de Lavras Novas há 57 anos, que trabalhou nas obras de saneamento em 1991, atualmente com 67 anos).

Portanto, as obras de saneamento foram benéficas para a saúde de grande parte dos residentes de Lavras Novas, mas aconteceram a custo do comprometimento ambiental de alguns córregos. Estas intervenções repercutiram nos hábitos dos moradores, que passaram a integrar o banheiro em suas casas. Mas também refletiram em alguns costumes, como a extinção do hábito de nadar, pescar e lavar roupas em alguns dos córregos que passaram a receber esgoto. Algumas áreas também foram drenadas, como a da nascente conhecida por biquinha, hoje canalizada próximo a uma área de gramado, onde poucos metros adiante a aparente tubulação emite esgoto na cabeceira do Córrego Seca Fumo.

A expansão urbana com a construção de pousadas na cabeceira de córregos utilizados pela população gerou prejuízos. Na década de 1990, o Córrego do Aranha servia para abastecer o povoado, juntamente com o Córrego do Mulato, e deixou de ser aproveitado devido à contaminação de suas águas por efluentes domésticos, como relata moradora do distrito: "Só o Córrego do Aranha, a gente tá cansado de ver que tem problema, que tem pousada jogando esgoto no córrego, e a prefeitura não faz nada. Já cansamos de fazer reunião por causa do Córrego do Aranha ali." 
VARAJÃO, G.F.D.C. \& DINIZ, A.M.A. Evolução da qualidade dos recursos ...

A impossibilidade de aproveitar as águas do Córrego do Aranha agravou uma das principais queixas dos habitantes, a de falta de abastecimento de água em períodos de grande fluxo turístico, como finais de semana e feriados. Obras mais recentes da Prefeitura Municipal, em 2008, buscaram aumentar a capacidade de distribuição da água. O solo próximo à casa de máquinas da captação de água foi perfurado a uma profundidade de 150 metros, na tentativa de utilizar água subterrânea para o povoado sem, no entanto, obter uma vazão adequada. Assim, as águas da Fonte da Rosa foram canalizadas para integrarem o sistema de distribuição. No entanto, ainda são insuficientes para a demanda em determinadas épocas, de modo que algumas pousadas e até casas utilizam águas subterrâneas, cada uma arcando com os custos de tal exploração.

Tendo em vista a carência de serviços de saneamento, atualmente, a prefeitura possui projetos para a construção de uma Estação de Tratamento de Esgoto e uma Estação de Tratamento de Água, sendo que as obras da última já iniciaram.

\section{Resultados das análises}

A partir das constatadas transformações apresentadas em Lavras Novas nas últimas décadas e a mudança dos hábitos da população devido à percebida deterioração da qualidade dos recursos hídricos, foram feitas análises físico-químicas e microbiológicas das águas com o intuito de aferir o grau de comprometimento dos mesmos, possuindo como parâmetros a legislação brasileira e outros estudos em litologias similares.

A figura 2 explicita a área de estudo, delimitada de acordo com as microbacias situadas no entorno do núcleo urbano, e os locais em que foram coletadas amostras de água. Os parâmetros analisados in situ apresentaram variações significativas de acordo com os locais de coleta (Tabela 1). O potencial hidrogeniônico $(\mathrm{pH})$ variou de ambientes ácidos, com 4.45, a ambientes básicos, com 8.24. Os locais com maior acidez, com $\mathrm{pH}$ inferior a 5 , foram as "bicas d'água" ou fontes utilizadas pelos moradores do centro 
VARAJÃO, G.F.D.C. \& DINIZ, A.M.A. Evolução da qualidade dos recursos ... urbano (B1, B2 e B3). As águas subterrâneas das cisternas das pousadas apresentaram todas um $\mathrm{pH}$ inferior a $6(\mathrm{C} 1, \mathrm{C} 2$ e $\mathrm{C} 3)$. Estes baixos valores podem estar relacionados à presença de ácidos orgânicos na água. À exceção do córrego do mulato e de outro córrego paralelo ao mesmo a leste, que drenam a face sul de Lavras Novas e apresentaram pH inferior a 6, as demais águas de superfície do distrito possuem $\mathrm{pH}$ superior a 6 .

Tabela 1: Vazão dos cursos d'água e parâmetros analisados in situ

\begin{tabular}{|c|c|c|c|c|c|c|c|c|}
\hline \multirow[b]{2}{*}{ P. } & \multirow[b]{2}{*}{ Córrego/Local } & \multirow[b]{2}{*}{$\begin{array}{c}\text { Vazão } \\
\text { (l/s) }\end{array}$} & \multicolumn{6}{|c|}{ Multiparâmetro } \\
\hline & & & $\mathbf{p H}$ & $\begin{array}{c}\text { Resist. } \\
\mathrm{K} \Omega\end{array}$ & $\begin{array}{c}\text { ORP } \\
\mathrm{mV}\end{array}$ & $\begin{array}{l}\text { TDS } \\
\mathrm{mg} / \mathrm{L}\end{array}$ & $\begin{array}{l}\text { Cond. } \\
\mu \mathrm{S} / \mathrm{cm}\end{array}$ & $\begin{array}{c}\text { Temp. } \\
{ }^{\circ} \mathrm{C}\end{array}$ \\
\hline B1 & Bica Grande & 0.13 & 4.7 & 56.5 & 308 & 10.8 & 17.62 & 18.7 \\
\hline B2 & Biquinha & 0.06 & 4.9 & 37.28 & 335 & 17.05 & 25.94 & 18.3 \\
\hline B3 & Fonte da Rosa & 0.82 & 4.5 & 91.8 & 339 & 6.96 & 10.56 & 18.8 \\
\hline C1 & C. Carumbé & - & 5.6 & 95.72 & 260 & 7.29 & 11.57 & 19.9 \\
\hline $\mathrm{C} 2$ & C. Bró & - & 5.3 & 141.5 & 299 & 4.29 & 6.89 & 22 \\
\hline C3 & C. Prazeres & - & 5.3 & 41.55 & 281 & 14.83 & 23.84 & 21.4 \\
\hline P1 & C. da Brenha & 7.72 & 6.5 & 570 & 188 & 0.8 & 3.66 & 12.8 \\
\hline $\mathbf{P 2}$ & - & 17.49 & 6.5 & 6.97 & 220 & 0.6 & 1.02 & 13 \\
\hline P3 & C. da Brenha & 68.79 & 6.2 & 42.11 & 268 & 14.4 & 23.5 & 14.3 \\
\hline P4 & C. da Brenha & 43.41 & 6.2 & 34 & 254 & 18.4 & 28.85 & 13.6 \\
\hline P5 & C. 3 Pingos & 9.3 & 6.3 & 256.1 & 220 & 2.06 & 3.24 & 15.4 \\
\hline P6 & C. 3 Pingos & 10.73 & 6.0 & 318.1 & 202 & 1.63 & 2.47 & 14.8 \\
\hline P7 & C. dos Moinhos & 3.7 & 7.3 & - & 33 & 326.1 & 468.8 & 16.2 \\
\hline P8 & C. do Coquinho & 10.26 & 6.0 & 4.61 & 251 & 0.06 & 0.15 & 14.8 \\
\hline P9 & - & 1.31 & 5.6 & 6.75 & 279 & 0.03 & 0.1 & 14.7 \\
\hline P10 & C. do Mulato & 7.55 & 6.5 & 7.35 & 235 & 0.03 & 0.09 & 14.5 \\
\hline P11 & C. Seca Fumo & 6.12 & 7.4 & - & 206 & 142.8 & 215 & 15.5 \\
\hline P12 & C. Aranha & 1.47 & 6.5 & 137.3 & 148 & 4.35 & 6.63 & 13.9 \\
\hline P13 & C. do Mulato & 0.8 & 6.0 & 234 & 205 & 2.29 & 3.5 & 14.6 \\
\hline P14 & C. Aranha & 0.55 & 6.3 & 129.1 & 187 & 4.68 & 6.86 & 13.4 \\
\hline P15 & $\begin{array}{l}\text { Córrego do } \\
\text { Mulato }\end{array}$ & 1.48 & 5.9 & 238.2 & 155 & 2.21 & 3.33 & 13.5 \\
\hline P16 & C. do Vitor & 0.34 & 8.2 & - & 256 & 222 & 330.1 & 22.2 \\
\hline
\end{tabular}

Apesar dos dados de $\mathrm{pH}$ estarem, de certo modo, inferiores aos encontrados por Andrade et al. (2009) e Leite et al. (2010) no Parque do Itacolomi, ainda se aproximam dos valores encontrados por Mourão (2007) e Salgado et al. (2004), em litologias quartzíticas. As anomalias identificadas estão relacionadas aos 
VARAJÃO, G.F.D.C. \& DINIZ, A.M.A. Evolução da qualidade dos recursos ... córregos que recebem esgoto, sendo apenas estas águas contaminadas que possuem um $\mathrm{pH}$ superior a 7 , no caso dos Córregos dos Moinhos (P7) e Seca Fumo (P11), chegando a 8.24 no Córrego do Vitor (P16). O aparelho Ultrameter II não conseguiu aferir a Resistividade destes três córregos contaminados.

De maneira geral, o potencial de óxido redução (ORP) está conexo com as variações de $\mathrm{pH}$, possuindo uma relação de importância inversa na qual os baixos valores de $\mathrm{pH}$ implicam em alto ORP. Entretanto, o $\mathrm{pH}$ não é a única variável que determina o ORP, o que foi percebido nos resultados dos córregos que recebem esgoto e que possuem diversos valores anômalos que não seguem a mesma tendência de relação, possivelmente também pela adição de cloro à água, como apontado por Andrade et al. (2009).

Já os parâmetros de condutividade e sólidos totais dissolvidos (TDS) possuem uma relação ainda mais direta e de proporcional importância, sobressaindo de forma clara as anomalias oriundas da contaminação antrópica das águas, principalmente dos três córregos supracitados que recebem esgoto. Enquanto os demais cursos d'água possuem um TDS que varia entre 0.03 a $17.05 \mathrm{mg} / \mathrm{L}$, valores semelhantes às águas do Parque Itacolomi (ANDRADE et al., 2009), os córregos contaminados chegam a ter valores de até $326.1 \mathrm{mg} / \mathrm{L}$, quase vinte vezes a mais de elementos dissolvidos.

O resultado da análise química está explicitado na Tabela 2, sendo que os elementos listados a seguir não foram identificados acima dos seus respectivos limites de quantificação, expressos em $\mu \mathrm{g} / \mathrm{L}$ entre parênteses ao lado de cada elemento: As (103), Be (0.529), Cd (4.74), Co (8.8), Cr (12.9), Mo (15.7), Ni (21.2), Pb (65.2), Sc (0.232), Ti (6.01), V (7.11), Y (1.25).

Comparando os resultados com a Resolução CONAMA n 357 (BRASIL, 2005), percebe-se que as concentrações de Alumínio das fontes de água B1 e B2, com 147 e $106.9 \mu \mathrm{g} / \mathrm{L}$ respectivamente, estão acima dos padrões estabelecidos de $100 \mu \mathrm{g} / \mathrm{L}$ para as classes de água 1 e 2, que são destinadas ao consumo humano, à recreação de contato primário, à irrigação de hortaliças, à aquicultura, à atividade de pesca e à proteção das comunidades aquáticas. 
VARAJÃO, G.F.D.C. \& DINIZ, A.M.A. Evolução da qualidade dos recursos ...

Tabela 2: Concentração de elementos químicos nas amostras de água

\begin{tabular}{|c|c|c|c|c|c|c|c|c|c|c|c|c|c|c|c|}
\hline P. & $\begin{array}{c}\text { Al } \\
\mu \mathrm{g} / \mathrm{L} \\
\end{array}$ & $\begin{array}{c}\text { Ba } \\
\mu \mathrm{g} / \mathrm{L} \\
\end{array}$ & $g / L$ & $\mathrm{Cu}$ & $\mu \mathrm{g} / \mathrm{L}$ & $\mathrm{mg} / \mathrm{L}$ & $\mathbf{L i}$ & 111 & $\begin{array}{l}\text { Mn } \\
\mu \mathrm{g} / \mathrm{L}\end{array}$ & $\mathrm{Na}$ & $\begin{array}{c}\mathbf{P} \\
\mathrm{mg} / \mathrm{L}\end{array}$ & $\begin{array}{c}\mathbf{S} \\
\mathrm{mg} / \mathrm{L}\end{array}$ & $\begin{array}{c}\mathbf{S i} \\
\mathrm{mg} / \mathrm{L}\end{array}$ & $\begin{array}{c}\mathbf{S r} \\
\mu \mathrm{g} / \mathrm{L}\end{array}$ & $\begin{array}{c}\mathbf{Z n} \\
\mu \mathrm{g} / \mathrm{L} \\
\end{array}$ \\
\hline B1 & 147 & 39.66 & 599 & $<\mathrm{LQ}$ & $<\mathrm{LQ}$ & 1.849 & $<\mathrm{LQ}$ & 0.181 & 68.5 & 1.89 & $<\mathrm{LQ}$ & $<\mathrm{LQ}$ & 0.958 & 5.36 & $<\mathrm{LQ}$ \\
\hline B2 & 9 & .42 & 2.573 & $<\mathrm{LQ}$ & $<\mathrm{LQ}$ & & $<\mathrm{LQ}$ & 59 & 00.2 & 3.438 & $<\mathrm{LQ}$ & 0.763 & & 72 & $<\mathrm{LQ}$ \\
\hline B3 & & 1 & 117 & $<\mathrm{LQ}$ & $<\mathrm{LQ}$ & 6 & $<\mathrm{LQ}$ & 18 & 27 & 0.97 & $<\mathrm{LQ}$ & $<\mathrm{LQ}$ & & 07 & 20.77 \\
\hline $\mathrm{C} 1$ & $Q$ & 5.16 & 206 & $<\mathrm{LQ}$ & 2.56 & 0.087 & 1.767 & 006 & 26.75 & 0.775 & $<\mathrm{LQ}$ & $<\mathrm{LQ}$ & 1.609 & 8.87 & 37.47 \\
\hline $\mathrm{C} 2$ & Q & 1.1 & 0.877 & 7.8 & $<\mathrm{LQ}$ & 4 & 0.958 & 62 & 58.1 & 0.757 & $<\mathrm{LQ}$ & 0.143 & 51 & 3.453 & 8.04 \\
\hline $\mathrm{C} 3$ & $Q$ & 0.84 & 022 & LQ & $<\mathrm{LQ}$ & & 31 & & 46.36 & 3 & $<\mathrm{LQ}$ & 1.028 & & 49 & 12.78 \\
\hline P1 & $\mathrm{Q}$ & 6.8 & 0.44 & $<\mathrm{LQ}$ & 102.5 & 0.179 & $<\mathrm{LQ}$ & 53 & 24.32 & 0.255 & $<\mathrm{LQ}$ & $<\mathrm{LQ}$ & 1.248 & 2.916 & $<\mathrm{LQ}$ \\
\hline P2 & Q & .88 & 137 & $<\mathrm{LQ}$ & 6.76 & 8 & $<\mathrm{LQ}$ & Q & 9.96 & 5 & $<\mathrm{LQ}$ & $<\mathrm{LQ}$ & 89 & 2.061 & $<\mathrm{LQ}$ \\
\hline P3 & LQ & 5.64 & 1.072 & $<\mathrm{LQ}$ & 94 & & $<\mathrm{LQ}$ & & 9.7 & 3.642 & $<\mathrm{LQ}$ & 0.322 & 0.997 & 6.66 & $<\mathrm{LQ}$ \\
\hline P4 & $<\mathrm{LQ}$ & 6.98 & 1.23 & $<\mathrm{LQ}$ & 581 & 03 & $<\mathrm{LQ}$ & 0.414 & 8.97 & 4.333 & 0.172 & 0.375 & 0.989 & 7.73 & $<\mathrm{LQ}$ \\
\hline P5 & LQ & 6.12 & 166 & $<\mathrm{LQ}$ & 32.49 & 3 & $<\mathrm{LQ}$ & 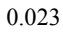 & 9 & 0.2 & $<\mathrm{LQ}$ & $<\mathrm{LQ}$ & 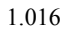 & 05 & $<\mathrm{LQ}$ \\
\hline P6 & $<\mathrm{LQ}$ & .05 & 109 & $<\mathrm{LQ}$ & 172.9 & 39 & $<\mathrm{LQ}$ & $<\mathrm{LQ}$ & 20.02 & 0.206 & $<\mathrm{LQ}$ & $<\mathrm{LQ}$ & 1.036 & 1.971 & $<\mathrm{LQ}$ \\
\hline P7 & $<\mathrm{LQ}$ & 2.5 & 493 & $<\mathrm{LQ}$ & 3229 & 7 & $<\mathrm{LQ}$ & 4 & .5 & 26.31 & 2.668 & 2.301 & 71 & 30.82 & 4.63 \\
\hline P8 & $<\mathrm{LQ}$ & .78 & 9 & $<\mathrm{LQ}$ & .53 & 0.6 & $<\mathrm{LQ}$ & & 8.18 & 0.422 & $<\mathrm{LQ}$ & $<\mathrm{LQ}$ & 4 & 5.16 & $<\mathrm{LQ}$ \\
\hline P9 & 30.8 & .35 & 087 & $<\mathrm{LQ}$ & 90.3 & 92 & $<\mathrm{LQ}$ & $<\mathrm{LQ}$ & 24.13 & 0.188 & $<\mathrm{LQ}$ & $<\mathrm{LQ}$ & 1.634 & 2.669 & $<\mathrm{LQ}$ \\
\hline P10 & $<\mathrm{LQ}$ & 60 & 0.2 & $<\mathrm{LQ}$ & 13.73 & 0.106 & $<\mathrm{LQ}$ & v & .56 & 0.662 & $<\mathrm{LQ}$ & $<\mathrm{LQ}$ & 1. & 3.371 & $<\mathrm{LQ}$ \\
\hline P11 & $<\mathrm{LQ}$ & 7.33 & 66 & $<\mathrm{LQ}$ & 1234 & 3.668 & $<\mathrm{LQ}$ & 54 & 326.3 & 12.72 & 0.836 & 2.28 & 1.069 & 6.44 & $<\mathrm{LQ}$ \\
\hline P12 & $<\mathrm{LQ}$ & 5.22 & 447 & $<\mathrm{LQ}$ & 530 & $<\mathrm{LQ}$ & $<\mathrm{LQ}$ & 0. & 41.67 & 1.114 & $<\mathrm{LQ}$ & $<\mathrm{LQ}$ & 5 & 5.4 & $<\mathrm{LQ}$ \\
\hline P13 & $<\mathrm{LQ}$ & 3.2 & 4 & $<\mathrm{LQ}$ & 189 & $<\mathrm{LQ}$ & $<\mathrm{LQ}$ & & 17.14 & 0.5 & $<\mathrm{LQ}$ & $<\mathrm{LQ}$ & 1. & .104 & $<\mathrm{LQ}$ \\
\hline P14 & $<\mathrm{LQ}$ & 2.71 & 839 & $<\mathrm{LQ}$ & 107 & $<\mathrm{LQ}$ & $<\mathrm{LQ}$ & 0. & 28.3 & 0.52 & $<\mathrm{LQ}$ & $<\mathrm{LQ}$ & 0.628 & 3.089 & $<\mathrm{LQ}$ \\
\hline P15 & $<\mathrm{LQ}$ & 2.4 & 171 & $<\mathrm{LQ}$ & 276.2 & $<\mathrm{LQ}$ & $<\mathrm{LQ}$ & 0.057 & 46.83 & 0.428 & $<\mathrm{LQ}$ & $<\mathrm{LQ}$ & 1.012 & 2.542 & $<\mathrm{LQ}$ \\
\hline P16 & $<\mathrm{I} O$ & 2.9 & ? & $<\mathrm{LQ}$ & 183.7 & 9.36 & 1.098 & 4.21 & 302.9 & 24.81 & $<\mathrm{LQ}$ & 1.989 & 1.166 & 40.23 & $<\mathrm{LQ}$ \\
\hline * & & 0.348 & 0.013 & 3 & 7.98 & 0.071 & 0 & $\begin{array}{r}0.001 \\
55\end{array}$ & 1. & 0.015 & & 0.064 & 0.012 & 0.17 & 3.8 \\
\hline & & & - & & & & & & & & & 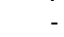 & - & & 80 \\
\hline$* * *$ & 200 & 000 & - & 13 & 5000 & & 2500 & & 500 & 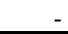 & 0.15 & - & - & & 5000 \\
\hline
\end{tabular}

* LQ= Limite de Quantificação

** C 1 \& 2 = Classe 1 e Classe 2 da Resolução CONAMA n 357 (BRASIL, 2005)

*** C 3 \& 4 = Classe 3 e Classe 4 da Resolução CONAMA n 357 (BRASIL, 2005)

Todavia, como já apontado por Andrade et al. (2009), que encontraram concentrações ainda mais elevadas, trata-se de um padrão estabelecido que, neste caso específico, não considera as condições naturais locais que, possivelmente, devido à presença de quartzitos sericíticos sob a ação de águas de pH abaixo de 5 permitem a mobilidade parcial desse metal.

$\mathrm{Na}$ água de uma das cisternas estudadas ( $\mathrm{C} 2)$ foi encontrada uma concentração de cobre $(7.8 \mu \mathrm{g} / \mathrm{L})$ próxima do limite imposto pela resolução $\mathrm{n}^{\circ} 357(9 \mu \mathrm{g} / \mathrm{L})$, muito provavelmente relacionada ao tipo de encanamento utilizado, uma vez que tal metal é incomum ao quartzito. Já concentrações de Ferro (Fe) e Manganês (Mn) elevadas são muitas vezes comuns em quartzitos ferruginosos, ou quando ocorrem faixas de canga e intercalações de 
VARAJÃO, G.F.D.C. \& DINIZ, A.M.A. Evolução da qualidade dos recursos ... xistos e filitos. Entretanto, foram identificadas concentrações destes elementos muito acima do comum a estas litologias, além de também estarem fora dos padrões estabelecidos pelo CONAMA.

As amostras de água que excederam o limite de $300 \mu \mathrm{g} / \mathrm{L}$ de Fe foram coletadas nos pontos P4, P7, P11 e P12, sendo que as concentrações de P7 e P11, córregos que recebem esgoto, estão muito acima dos padrões, refletindo no P4, uma vez que este último é o Córrego da Brenha, que recebe as águas de ambos córregos contaminados. Já a concentração encontrada no Córrego do Aranha pode ser devida às condicionantes naturais acima descritas, considerando que este não apresenta elevada contaminação microbiológica.

Os teores de Manganês (Mn) encontrados nos córregos que recebem esgoto também são destoantes aos padrões previstos na legislação Brasileira, tendo sido identificadas concentrações acima de $300 \mu \mathrm{g} / \mathrm{L}$ nos Córregos dos Moinhos (P7), Seca Fumo (P11) e Vitor (P16), tendo em vista que a Resolução CONAMA n 357 (BRASIL, 2005) prevê um máximo de $100 \mu \mathrm{g} / \mathrm{L}$ para as classes de água 1 e 2 .

As concentrações de Fósforo (P) se destacam ainda mais em relação aos outros elementos, uma vez que os valores ultrapassam a classe 3 (BRASIL, 2005) que dispõe sobre as águas que poderiam ser destinadas à irrigação de culturas arbóreas, cerealíferas e forrageiras, à pesca amadora, à recreação de contato secundário e à dessedentação de animais. O Córrego dos Moinhos (P7) chega a possuir um teor de Fósforo de $2.668 \mu \mathrm{g} / \mathrm{L}$ e o Córrego Seca Fumo (P11) $0.836 \mu \mathrm{g} / \mathrm{L}$, sendo $0.15 \mu \mathrm{g} / \mathrm{L}$ o limite legal das águas de classe 3 . Tais concentrações são diluídas pela confluência destes Córregos com o Córrego da Brenha, no ponto P4, atingindo o valor de $0.172 \mu \mathrm{g} / \mathrm{L}$, ainda acima do valor estabelecido por lei.

Tendo exposto as principais anomalias físico-químicas identificadas de acordo com os estudos em litologias quartzíticas e os padrões legais brasileiros, a seguir serão apresentados os resultados das análises microbiológicas, observando os parâmetros microbiológicos previstos por três diferentes normativas legais (Tabela 3 ). 
VARAJÃO, G.F.D.C. \& DINIZ, A.M.A. Evolução da qualidade dos recursos ...

Tabela 3: Número Mais Provável de Coliformes Totais e Escherichia coli $(\mathrm{NMP} / 100 \mathrm{~mL})$ presentes nas amostras de água

\begin{tabular}{|c|c|c|c|c|c|c|}
\hline \multirow[b]{2}{*}{ P. } & \multicolumn{2}{|c|}{$\begin{array}{c}\text { Coordenadas } \\
\text { (SAD69) }\end{array}$} & \multirow[b]{2}{*}{ Córrego/Local } & \multirow[b]{2}{*}{ E. Coli } & \multirow[b]{2}{*}{ C. Totais } & \multirow{2}{*}{$\begin{array}{c}\text { Vazão } \\
(\mathbf{l} / \mathbf{s})\end{array}$} \\
\hline & $\mathbf{X}$ & $\mathbf{Y}$ & & & & \\
\hline B1 & 654765 & 7735305 & Bica Grande & 0 & 1 & 0.13 \\
\hline $\mathrm{B} 2$ & 654587 & 7735600 & Biquinha & 0 & 46.5 & 0.06 \\
\hline B3 & 654318 & 7734984 & Fonte da Rosa & 0 & 0 & 0.82 \\
\hline $\mathrm{C} 1$ & 654510 & 7735730 & Cisterna Carumbé (130m) & 0 & 2 & - \\
\hline $\mathrm{C} 2$ & 654639 & 7736016 & Cisterna Bró $(90 \mathrm{~m})$ & 0 & 0 & - \\
\hline $\mathrm{C} 3$ & 654679 & 7736036 & Cisterna Prazeres $(60 \mathrm{~m})$ & 0 & 0 & - \\
\hline P1 & 653817 & 7737847 & Córrego da Brenha & 5.2 & 435.2 & 7.72 \\
\hline P2 & 655324 & 7736785 & - & 1 & 816.4 & 17.49 \\
\hline P3 & 656828 & 7735483 & Córrego da Brenha & 101.9 & 1986.3 & 68.79 \\
\hline P4 & 656804 & 7735484 & Córrego da Brenha & 88 & 2419.6 & 43.41 \\
\hline P5 & 656791 & 7735447 & Córrego 3 Pingos & 2 & 1553.1 & 9.3 \\
\hline P6 & 657004 & 7734980 & Córrego 3 Pingos & 8.5 & 1413.6 & 10.73 \\
\hline P7 & 655193 & 7734567 & Córrego dos Moinhos & $>2419.6$ & $>2419.6$ & 3.7 \\
\hline P8 & 654673 & 7734004 & Córrego do Coquinho & 3.1 & 686.7 & 10.26 \\
\hline P9 & 654323 & 7734145 & - & 3.1 & 435.2 & 1.31 \\
\hline P10 & 653958 & 7734557 & Córrego do Mulato & 0 & 648.8 & 7.55 \\
\hline P11 & 655366 & 7735181 & Córrego Seca Fumo & $>2419.6$ & $>2419.6$ & 6.12 \\
\hline $\mathrm{P} 12$ & 653807 & 7735282 & Córrego Aranha & 2 & 186 & 1.47 \\
\hline P13 & 653678 & 7735294 & Córrego do Mulato & 2 & 547.5 & 0.8 \\
\hline P14 & 653721 & 7735730 & Córrego Aranha & 4.1 & 913.9 & 0.55 \\
\hline $\mathrm{P} 15$ & 653415 & 7735719 & Córrego do Mulato & 0 & 209.8 & 1.48 \\
\hline P16 & 654711 & 7736170 & Córrego do Vitor & $>2419.6$ & $>2419.6$ & 0.34 \\
\hline
\end{tabular}

Em diversos locais de coleta, ao lado dos cursos d'água, foram observadas fezes de animais, uma vez que é comum no entorno de Lavras Novas terem equinos e bovinos sendo criados soltos. Tal constatação possivelmente explica em parte a presença de Escherichia coli em quase todas as águas superficiais da região, pois tal bactéria é indicativa de contaminação fecal. Entretanto, as elevadíssimas concentrações desta bactéria, acima de 2419.6/100ml, encontradas nos Córregos dos Moinhos (P7), Seca Fumo (P11) e Vitor (P16) somente podem ser consequência de esgoto sendo despejado in natura diretamente nos córregos. Considerando a legislação, os três córregos devem ser considerados impróprios para qualquer tipo de uso, incluindo a dessedentação de animais, que exige valores abaixo de 1000/100ml. Tendo em vista que são córregos tributários do Córrego 
VARAJÃO, G.F.D.C. \& DINIZ, A.M.A. Evolução da qualidade dos recursos ... da Brenha, as concentrações de Escherichia coli são diluídas por suas águas, conforme constatado nos pontos de coleta abaixo da confluência, com 101.9 (P3) e 88 (P4).

As bicas ou fontes de água utilizadas pela população estão isentas de $\mathrm{E}$. coli, mas a B2 apresentou um número alarmante de coliformes totais para o consumo humano, com 46.5/100ml. As águas subterrâneas das cisternas das pousadas estão isentas de contaminantes microbiológicos, com exceção da cisterna $\mathrm{C} 1$, que apresentou apenas $2 / 100 \mathrm{ml}$ de coliformes totais. Apesar de não ser considerado fator restritivo pela legislação, vale notar que os coliformes totais dos pontos P5 e P6, que pertencem ao córrego que forma a cachoeira 3 Pingos, estão com valores acima do encontrado nos demais córregos que não recebem esgoto direto, com 1553.1 e 1413.6/100ml, respectivamente. Tal valor possivelmente pode estar atrelado à visitação humana mais intensa nestes locais, como constatado por Dalman et al. (2008), que atribuem o agito dos sedimentos do leito dos córregos pelos banhistas como possível causa da elevação dos coliformes na água.

\section{Considerações finais}

As análises efetuadas em cursos d'água mais afastados do núcleo urbano de Lavras Novas, com litologia predominante de quartzito, apontaram concentrações de elementos em determinados locais, como ferro (Fe) e alumínio (Al), acima dos padrões determinados pela Resolução CONAMA n 357 (BRASIL, 2005), mostrando que a legislação brasileira ainda não contempla determinadas condições naturais de variados tipos litológicos, conforme já assinalado por Andrade et al. (2009).

Entretanto, comparando-se os resultados das análises de água efetuadas na área urbana de Lavras Novas com aqueles encontrados em áreas com litologias similares (LEITE et al., 2010; MOURÃO, 2007; e SALGADO et al., 2004), verificou-se que as concentrações em alguns pontos (córregos que recebem esgoto) estão muito acima dos valores considerados como background para 
VARAJÃO, G.F.D.C. \& DINIZ, A.M.A. Evolução da qualidade dos recursos ... este ambiente específico, evidenciando a forte alteração antrópica existente nos cursos d'água.

Tal interferência humana foi corroborada pelas análises microbiológicas, que comprovam elevada contaminação fecal de alguns córregos, restringindo qualquer tipo de uso destas águas, além de representar riscos à saúde pública e sério comprometimento das comunidades aquáticas. Necessita-se ressaltar que é considerado ilegal o lançamento de efluentes sem o tratamento prévio e em desacordo com as condições e padrões estabelecidos pela Resolução CONAMA n 357 (BRASIL, 2005).

Os resultados encontrados dificilmente seriam semelhantes caso houvesse sido feito este mesmo monitoramento na década de 1980, uma vez que a percepção dos moradores indica uma clara deterioração dos cursos d'água, que deixaram de adotar diversos usos dos mesmos. Assim, muitos habitantes relataram a mudança da qualidade da água de alguns córregos próximos ao centro urbano, que no passado utilizavam para se banhar, pescar ou lavar roupa e nos dias atuais recebem esgoto in natura, reflexo das obras de saneamento efetuadas no início da década de 1990 pelo poder público.

É paradoxal que um núcleo urbano como o de Lavras Novas, localizado em uma área de cabeceira com tantas nascentes, atualmente sofra com a falta de água nas casas em determinadas épocas, pelo subdimensionamento do abastecimento público e a contaminação dos cursos d'água. Nos períodos de seca, 100\% das águas do Córrego do Mulato são canalizadas para a utilização pública, contrariando a legislação vigente. As águas do Córrego do Aranha, que no passado compunham o sistema de distribuição, atualmente são inutilizadas devido às construções em suas áreas de cabeceira que alteraram seus parâmetros. A situação é ainda mais alarmante se forem considerados os níveis de contaminação microbiológica identificados em outros três córregos que nascem no centro urbano (Córrego dos Moinhos, Seca Fumo e Vítor), que, se não recebessem esgoto, poderiam abastecer parte da população e ajudariam a equilibrar o ilegal uso integral das águas do Córrego do Mulato. 
VARAJÃO, G.F.D.C. \& DINIZ, A.M.A. Evolução da qualidade dos recursos ...

Assim, espera-se que este trabalho tenha contribuído para retratar as condições das águas do distrito, sendo importante a execução de estudos futuros para monitorar a sua evolução. Os resultados apresentados poderão servir de parâmetro para determinar a eficácia da ETE, caso sua construção seja realmente efetivada.

\section{Referências bibliográficas}

ALKMIM, F.F.; MARSHAK, S. The Transamazonian orogeny in the Quadrilátero Ferrífero, Minas Gerais, Brazil: Paleoproterozoic Collision and Collapse in the Souhtern São Francisco Craton region. Precambrian Research, Amsterdam, 1998. v. 90. p. 29-58.

ALMASSY JUNIOR, A.A. Análises das caracteríticas etnobotânicas e etnofarmacológicas de plantas medicinais na comunidade de Lavras Novas, Ouro Preto - MG. 2004. 147p. Tese (Doutorado em Fitotecnia). Universidade Federal de Viçosa. Viçosa, 2004.

ANDRADE, L.N.; LEITE, M.G.P.; BACELLAR, L.A.P. Influência geológica em assinaturas químicas das águas e solos do Parque Estadual do Itacolomi, Minas Gerais. Revista da Escola de Minas, Ouro Preto, v. 62, n. 2, p. 147-154, abr/jun. 2009.

APHA - American Public Health Association. Standard methods for examination of water and wastewater. 21. ed. Washington: American Public Health Association, 2005.

BAUDISOVA, D. Evaluation of E. coli as the main indicator of fecal pollution. Water Science and Technology, Oxford, v.35, n.11-12, p. 333-336. 1997.

BRASIL. Ministério do Meio Ambiente. Conselho Nacional do Meio Ambiente-CONAMA. Resolução no 357 de 17/03/2005. Dispõe sobre a classificação dos corpos de água e diretrizes 
VARAJÃO, G.F.D.C. \& DINIZ, A.M.A. Evolução da qualidade dos recursos ... ambientais para o seu enquadramento, bem como estabelece as condições e padrões de lançamento de efluentes, e dá outras providências. Diário Oficial da União, Brasília, Seção 1, 2005.

BRASIL. Ministério da Saúde. Portaria no 2.914 de 12/12/2011. Procedimentos de controle e de vigilância da qualidade da água para consumo humano e seu padrão de potabilidade. Diário Oficial da União, Brasília, Seção 1, p. 39-49, 2011.

BRASIL. Ministério do Meio Ambiente. Conselho Nacional do Meio Ambiente-CONAMA. Resolução no 274 de 29/11/2000. Dispõe sobre as águas doces, salobras e salinas destinadas à balneabilidade (recreação de contato primário). Diário Oficial da União, Brasília, 29 nov. 2000.

CETESB. Companhia de Tecnologia de Saneamento Ambiental. Relatório de qualidade das águas interiores do Estado de São Paulo 2003. São Paulo: CETESB, 2004.

DALMAN, N.E. et al. Effect of human recreation on Escherichia coli levels in the Chattahoochee river in Helen, GA. Georgia Journal of Science. v. 66, n. 1, p. 8-9. 2008.

DATES, G. et al. Massachusetts Water Watch Partnership Volunteer Water Quality Monitoring Manual. Amherst: University of Massachusetts, 1994.

DREVER, J.I. The Geochemistry of Natural Waters: Surface and Groundwater Environments. 3. ed. Englewood Cliff: Prentice Hall, 1997.

EDBERG, S.C. et al. Escherichia coli: the best biological drinking water indicator for public health protection. Journal of Applied Microbiology. v. 88, p. 106S-116S, 2000. 
VARAJÃO, G.F.D.C. \& DINIZ, A.M.A. Evolução da qualidade dos recursos ...

EMBRAPA. Centro Nacional de Pesquisa de Solos. Sistema brasileiro de classificação de solos. 2. ed. Rio de Janeiro, 2006.

JOHNSON, R.F. Geology and Ore deposits of the Cachoeira do Campo, Dom Bosco, and Ouro Branco Quadrangles Minas Gerais, Brazil. US Geological Survey Prof. Paper. Washington: US Governement Printing Office, 341-B,1962.

LEITE, M.G.P.; FUJACO, M.A.G.; NALINI JÚNIOR, H.A.; CASTRO, P.T. A. Influence of geology in the geochemistry signature of Itacolomi State Park waters, Minas Gerais-Brazil. Environmental Earth Sciences. v. 60, n. 8, p. 1723-1730. 2010.

LOBATO, L.M. et al. Projeto Geologia do Quadrilátero Ferrífero Integração e Correção Cartográfica em SIG com nota explicativa. Belo Horizonte: CODEMIG, 2005. 1 CD-ROM

LOPES, F.W.A.; MAGALHÃES JÚNIOR, A.P.; PEREIRA, J.A.A. Avaliação da Qualidade das Águas e Condições de Balneabilidade na Bacia do Ribeirão de Carrancas-MG. Revista Brasileira de Recursos Hídricos, v. 13, n.4, p. 111-120, Out/Dez. 2008.

MILLER, J.A. Introduction and national summary. In: US Geological Survey. Ground Water Atlas of the United States. USGS, 1999.

MINAS GERAIS. Secretaria de Estado de Meio Ambiente e Desenvolvimento Sustentável - SEMAD. Instituto Estadual de Florestas - IEF. Plano de Manejo do Parque Estadual do Itacolomi: Encarte 1 - Diagnóstico do Parque. Belo Horizonte, 2007.

MOLDAN, B.; ČERNÝ, J. Small catchment research. In: MOLDAN, B.; CERNY, J. (Org.) Biochemistry of small cachments: a tool of environment research. Chichester: Wiley, 1994. p. 1-29. 
VARAJÃO, G.F.D.C. \& DINIZ, A.M.A. Evolução da qualidade dos recursos ... MORIÑIGO, M.A. et al. Relationships between Salmonella sp. and indicator microorganisms in polluted natural waters. Water Research. v. 24, n. 1, p. 117-120. 1990.

MOURÃO, M.A.A. Caracterização hidrogeológica do aquífero cauê, Quadrilátero Ferrífero, MG. Belo Horizonte, 2007. Tese (Doutorado em Saneamento, Meio Ambiente e Recursos Hídricos) - Universidade Federal de Minas Gerais, Belo Horizonte, 2007.

ORNELAS, A.R. A percepção ambiental como instrumento para implantação de Unidades de Conservação: um estudo de caso sobre a percepção ambiental dos moradores do entorno da Serra do Trovão, Ouro Preto - MG. 2008, 52 p. Monografia (Graduação em Engenharia Ambiental) Universidade Federal de Ouro Preto, Ouro Preto, 2008.

PALHARES, J.C.P. et al. Medição da Vazão em Rios pelo Método do Flutuador. Comunicado Técnico 455. EMBRAPA, 2007.

SALGADO, A.A.R. et al. O papel da denudação geoquímica no processo de erosão diferencial no Quadrilátero Ferrífero/Mg. Revista Brasileira de Geomorfologia, v. 5, p. 55-69, 2004.

TEIXEIRA, C.M. Origens e transformações da arquitetura vernácula do ciclo do ouro: um estudo sobre Lavras Novas, Ouro Preto, Minas Gerais. 2004, 313 p. Tese (Doutorado em Arquitetura) - Escuela Técnica Superior de Arquitectura, Universidad de Valladolid, Valladolid, 2004

Recebido em setembro de 2012

Aceito em outubro de 2014 